\title{
Cerebellum, brainstem and spinal cord adhesions following basilar impression and Chiari malformation surgery
}

\author{
José Alberto Gonçalves da Silva', Luiz Ricardo Santiago Melo', \\ Antônio Fernandes de Araújo ${ }^{1}$, Adailton Arcanjo dos Santos Jr. ${ }^{2}$
}

The true importance of performing a watertight dural closure, for neurological procedures, is to avoid several complications such as cerebrospinal fluid (CSF) leakage, pseudomeningocele (PSM), meningitis, cerebral abscess, tonsilar herniation, hydrocephalus, etc ${ }^{1}$.

A variety of materials has been used for duraplasty, including autografts: periosteum, acellular human dermis (Allo Derm $^{\circ}$ );allografts: acellular human dura mater;xenografts: bovine pericardium and ovine pericardium and synthetic grafts: collagen matrix (Dura-Gen $\left.{ }^{\circ}\right)^{1-4}$.

Dura-Gen ${ }^{\bullet}$ originated from collagen matrix is the unique dural graft which can be used in the dura mater without the necessity of additional fixation ${ }^{2}$.

This study is based on three different types of complications of dural grafts used for the posterior fossa decompression in a patient with basilar impression (BI) and Chiari malformation (CM). Several adhesions to the cerebellum, medulla and spinal cord were observed, as well as a partial calcification of the previous graft, along with cerebellar ataxia.

\section{CASE}

A 55-year-old woman was admitted with history of two neurosurgical procedures due to $\mathrm{BI}$ and $\mathrm{CM}$ in different hospitals. The first surgery was performed in September 1982 when the patient presented balance disorders and cerebellar ataxia. The authors do not have the preoperative and postoperative exams of this surgery. On September 2005, the patient un- derwent the second surgery which the authors also do not have the preoperative and postoperative exams. On May 2006, the patient was admitted in our hospital presenting a variety of symptoms such as headache, stiffness of neck, diplopia, nystagmus, abolition of gag and palatal reflexes, dysphagia, dysarthria, nasal reflux, rhinolalia, spastic paraparesis, clonic patellar and Achilles reflexes, severe cerebellar ataxia and leg hypopallesthesia. The magnetic resonance image (MRI) depicted $\mathrm{BI}$ and herniated tonsils at $\mathrm{C} 1$ level along with thickness of duraplasty, absence of the fourth ventricle, brainstem distortion by BI, absence of cisterna magna and cerebellar atrophy (Fig 1).

During the third surgery which was performed on May 19, 2006, the authors observed severe local fibrosis and adhesions to the cerebellum, medulla and spinal cord (Fig 2), as well as thickness and partial calcification of the dural graft that was completely removed and substituted by the bovine pericardium. The authors performed partial exeresis of the adhesions and fibrosis, as well as bilateral tonsilectomy and a large opening of the fourth ventricle. After this surgery, there was development of PSM and CSF fistula, and a reoperation was then performed on July 14, 2006 to solve the complications. In sequential computed tomography brain scan, there was enlargement of the ventricular system, which probably triggered the PSM and CSF fistula development. On August 8, 2006, the patient underwent a ventriculoperitoneal shunt with total re-
José Alberto Gonçalves da Silva Avenida Minas Gerais 1150 58030-092 João Pessoa PB - Brasil E-mail: jags1803@hotmail.com

Received 28 April 2009

Received in final form 21 September 2009 Accepted 1 October 2009
ADERÊNCIAS CEREBELO-BULBO-MEDULARES OBSERVADAS APÓS TRATAMENTO CIRÚRGICO DE IMPRESSÃO BASILAR E MALFORMAÇÃO DE CHIARI

${ }^{1}$ Neurosurgical Division of the Hospital Geral Santa Isabel, João Pessoa PB, Brazil; ${ }^{2}$ Associated Physician. 


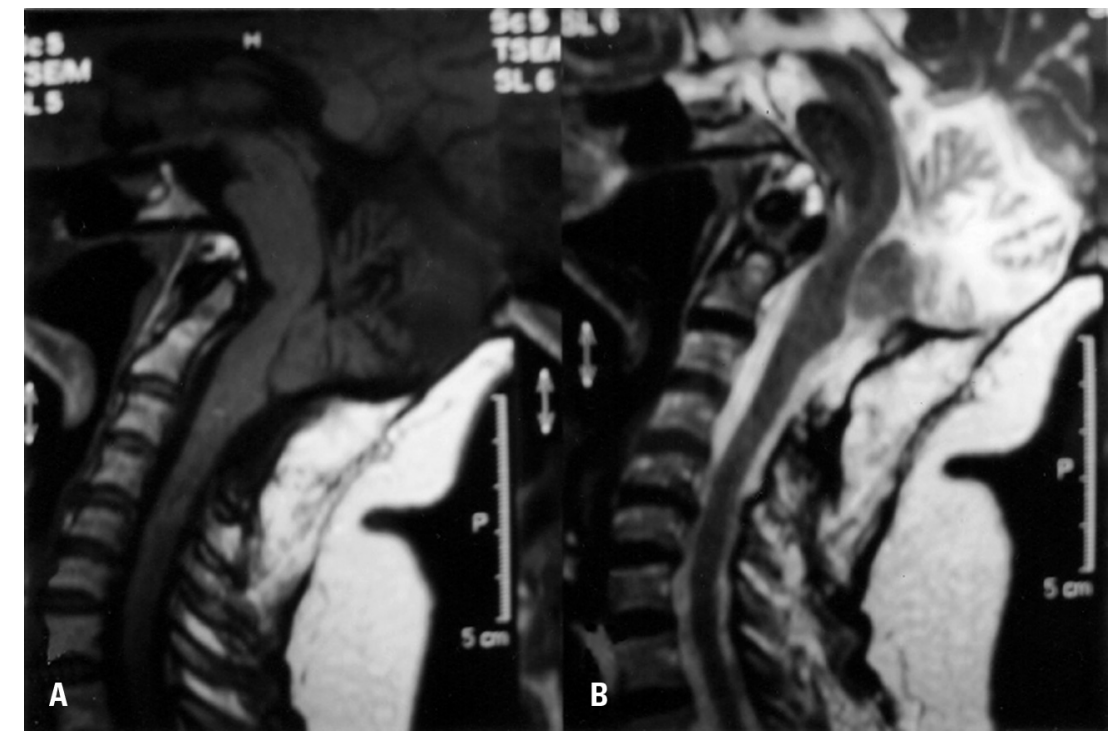

Fig 1. [A] Preoperative MRI demonstrating basilar impression, herniated tonsils at C1 level, as well as brainstem compression and absence of the fourth ventricle and cisterna magna. [B] Thickness of the duraplasty and cerebellar atrophy.
Fig 2. [A] Local fibrosis and adhesions to the cerebellum and spinal cord observed during the surgery. $[B]$ Tonsilectomy and large opening of the fourth ventricle.
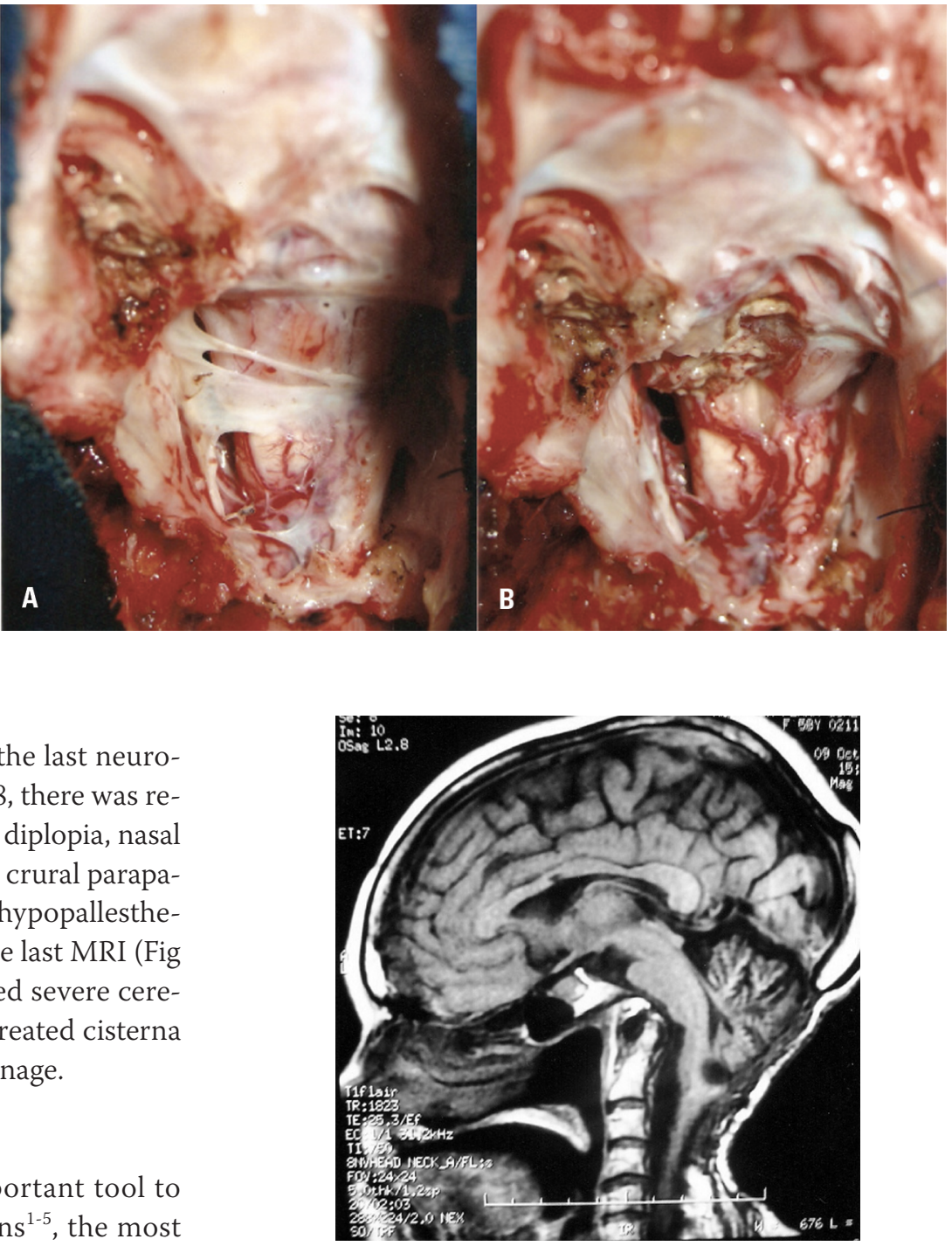

Fig 3. Postoperative MRI shows decrease of the brainstem distortion, opening of the fourth ventricle, disappearance of the created cisterna magna and severe cerebellar atrophy. 
The best dural repair is based on the interrupted or continuous suture of the dural graft, followed by the use of sealant material such as collagen matrix, absorbable gelatin, cyanocrylates, fibrin, glutaraldehyde, Bioglue (a combination of bovine albumin and glutaraldehyde that confers enhanced bonding properties) and collagen materials for the completely dural closure ${ }^{5,6}$.

It is important to observe that some biocompatible materials like the different kinds of hydrogel can create an effective barrier to avoid the CSF leakage. The main reasons to use a dural graft are to make a watertight dural closure and create an enlarged cisterna magna to avoid adhesions to the nervous tissues, as well as to facilitate the upward migration of the cerebellum and brainstem ${ }^{7,8}$.

Stendel et al. ${ }^{2}$ observed that in 191 patients undergoing a cranial procedure, CSF collection occurred in 5 patients (2.6\%) and CSF fistula in 5 (2.6\%), 3 of whom (1.6\%) required surgical revision. The collagen matrix (Dura-Gen ${ }^{\circ}$ ) was used without additional fixation in 124 patients (56.1\%), with single fixation in $55(24.9 \%)$ and with multiple fixations in 42 (19\%).

Parizek et al. ${ }^{1}$ reported surgical experience with 2959 allogenic and xenograft dense connective tissue grafts (1767 of fascia lata, 909 of pericardium, and 283 of duramater). Postsurgical complications occurred in 7.3\%: CSF fistula in $2.8 \%$, meningitis in $2.3 \%$, PSM in $2.2 \%$, wound infection in $0.6 \%$, malresorptive hydrocephalus in $0.5 \%$ and adhesions to the nervous tissue in $0.5 \%$.

In this study, the authors observed several complications described in literature which, coincidentally, occurred in just one patient, such as development of fibrosis and adhesions, deterioration of clinical presentation, CSF fistula, PSM and hydrocephalus which was successfully treated with ventriculoperitoneal shunt ${ }^{1,8-10}$. Furthermore, the last MRI carried out on October 9, 2008 depicted progressive cerebellar atrophy, when compared with a previous MRI performed before the third surgery as well as absence of the created cisterna magna due to the hydrocephalus overdrainage. Coincidentally, when the authors visited the patient in her house, they observed that the patient's son presented cerebellar ataxia too, and his MRI also revealed severe cerebellar atrophy, which made the authors think about a neurodegenerative disorder as spinocerebellar ataxia associated with BI and CM. The genetic investigation is a very important method for diagnosis of neurodegenerative disorders, but, unfortunately, this kind of study was not available.

\section{REFERENCES}

1. Parizek J, Mericka P, Husek Z, et al. Detailed evaluation of 2959 allogeneic and xenogeneic dense connective tissue grafts (fascia lata, pericardium, and duramater) used in the course of 20 years for duraplasty in neurosurgery. Acta Neurochir (Wien) 1997;139:827-838.

2. Stendel R, Danne M, Fiss I, et al. Efficacy and safety of a collagen matrix for cranial and spinal dural reconstruction using different fixation techniques. J Neurosurg 2008;109:215-221.

3. Warren WL, Medary MB, Dureza CD, et al. Dural Repair using acellular human dermis: experience with 200 cases: technique assessment. Neurosurgery 2000;46:1391-1396.

4. Danish SF, Samdani A, Hanna A, Storm P, Sutton L. Experience with acellular human dura and bovine collagen matrix for duraplasty after posterior fossa decompression for Chiari malformations. J Neurosurg (Pediatrics) 2006;104:16-20.

5. Preuel MC, Bichard WD, Muench TR, Spetzler RF. Toward optimal tissue sealants for neurosurgery: use of a novel hydrogel sealant in a canine durotomy repair model. Neurosurgery 2003;53:1189-1199.

6. Blackburn SL, Smyth MD. Hydrogel-induced cervicomedullary compression after posterior fossa decompression for Chiari malformation: case report. J Neurosurg 2007;106(Suppl 4):S302-S304.

7. Gonçalves da Silva JA, Holanda MMA, Pereira CB, Leiros MD, Araújo AF, Bandeira E. Retropulsion and vertigo in the Chiari malformation: case report. Arq Neuropsiquiatr 2005;63:870-873.

8. Sahuquillo J, Rubio E, Poca MA, Rovira A, Rodriguez-Baeza A, Cervera C. Posterior fossa reconstruction: a surgical technique for the treatment of Chiari I malformation and Chiari I/syringomyelia complex: preliminary results and magnetic resonance imaging quantitative assessment of hindbrain migration. Neurosurgery 1994;35:874-885.

9. Kumar A, Maartens NF, Kaye AH. Evaluation of the use of BioGlue in

10. neurosurgical procedures. J Clin Neuroscience 2003;10:661-664.

11. Rosen DS, Wollmann R, Frim DM. Recurrence of symptoms after Chiari decompression and duraplasty with nonautologous graft material. Pediatr Neurosurg 2003;38:186-190. 